\title{
Geomorfologia, cobertura sedimentar e transporte de sedimentos na plataforma continental interna entre a Ponta de Saquarema Cabo Frio (RJ)
}

\author{
Dieter MUEHE \& Vânia Guaycuru de CARVALHO
}

Departamento de Geografia, Laboratório de Geormorfologia Fluvial, Costeira e Submarina, Instituto de Geociências, Universidade Federal do Rio de Janeiro (Cidade Universitária, Ilha do Fundāo, 21941-590 Rio de Janeiro, Brasil)

\begin{abstract}
- Abstract: The inner continental shelf in front of the Massambaba beach, an East-West striking, $48 \mathrm{~km}$ long, double barrier beach, located between the towns of Saquarema and Arraial do Cabo presents a monotonous topography with only few outcrops of crystaline rocks, patches of beach rocks and a sediment cover of mainly relict quartz sand. The topographic gradient, steeper as expected for a passive shelf, reaches the $60 \mathrm{~m}$ isobath at a distance of about 4 nautical miles from the shoreline. A large outcrop of beach rock occurs at depths between 48 to $60 \mathrm{~m}$, corresponding to the position of the shoreline of possibly 10,000 years ago. A small outcrop, near the profile S-4, at a depth of $4 \mathrm{~m}$ and distant $50 \mathrm{~m}$ from the beachface, is a good indication of shoreline retreat. The pattern of grain size shows a decreasing gradient both toward the East as also toward deeper waters. Input of continental sediments to the shelf is almost absent. Consequently the pattern of sediment distribution must primarily be due to the introduction of sediments trough an ancient Pleistocene drainage system, interrupted by the construction of a barrier beach, and to the reworking of sediments due to waves and currents. The interpretation of existing current measurements, as also of the grain size distribution parameters, indicate that net sediment movement is directed to the East.

- Resumo: A plataforma continental interna defronte à restinga da Massambaba - um sistema de duplos cordōes litorâneos localizados entre Saquarema e Arraial do Cabo, com $48 \mathrm{~km}$ de extensão - apresenta topografia regular, interrompida por raros afloramentos de rochas do embasamento cristalino e por ocorrências localizadas de arenitos de praia. Um amplo afloramento destes últimos ocorre na faixa batimétrica de $48 \mathrm{a} 60 \mathrm{~m}$, correspondendo à posição da linha de costa cerca de 10.000 anos atrás. Outro afloramento de arenitos de praia, de reduzida dimensão, ocorre próximo ao perfil S-4, à distância de $50 \mathrm{~m}$ da face da praia, em profundidade de $4 \mathrm{~m}$. A cobertura sedimentar, sem aporte significativo de sedimentos terrígenos, é constituída predominantemente por areias quartzosas reliquiares. $\mathrm{O}$ gradiente batimétrico apresenta declividade elevada, atípica para uma plataforma passiva, atingindo o limite distal da plataforma continental interna, a isobatimétrica de $60 \mathrm{~m}$, a uma distância da ordem de 4 milhas náuticas da linha de praia. O padrão de distribuição granulométrico apresenta gradientes de decréscimo em direção a leste, isto $\epsilon$, em direção ao Cabo Frio, e em direção a maiores profundidades. A diminuição do tamanho granulométrico em direção ao Cabo Frio é atribuída como sendo resultado do aporte de sedimentos terrígenos através de um sistema de drenagem pleistocênico, interrompido pela construção do cordão litorâneo mais interiorizado, e à remobilização dos sedimentos por ação de ondas e correntes com transporte residual em direção a leste.
\end{abstract}

- Descriptors: Inner shelf, Geomorphology, Sediment distribution, Sediment transport, Rio de Janeiro, Brazil.

- Descritores: Plataforma continental interna, Geomorfologia, Distribuição dos sedimentos, Transporte de sedimentos, Rio de Janeiro, Brasil.

\section{Introdução}

Um peculiaridade do litoral sul-oriental do Estado do Rio de Janeiro, entre o Cabo Frio e a Baía de Guanabara, é a orientação aproximadamente E-W de seus amplos arcos de praia (Fig. 1). Esta orientação, reflexo de idêntica disposiçāo das curvas batimétricas, principalmente da plataforma continental interna, com influência direta sobre a incidência das ondas oceânicas sobre a linha de costa, é resultado de um possível tectonismo quebrante 
que teria afetado a região durante parte do Terciário (Asmus \& Ferrari, 1978) ou simplesmente decorrência de modelamento erosivo, após a fase rift (Weissel, 1990), direcionado ao longo de zonas de fraturas impressas antes do soerguimento continental que antecedeu a abertura do Atlântico Sul. Esta compartimentação, téctono-erosiva, responsável pelos grandes traços morfológicos da margem continental, dos maciços costeiros, da Serra do Mar e do gráben do rio Paraíba do Sul, se reflete sobre os processos oceanográficos e climáticos (Muehe, 1983) criando para esta região características próprias de aporte e transporte sedimentar. Mais especificamente, a brusca inflexāo, para oeste, das curvas batimétricas, na altura do Cabo Frio, provoca uma instabilização do fluxo da Corrente do Brasil que passa a desenvolver vórtices no seu flanco direito (Mesquita et al., 1979), com efeitos ainda não conhecidos sobre processos geológicos e biológicos da plataforma continental, enquanto que a orientação mais frontal, das linhas batimétricas e das praias, à incidência das ondas de tempestade, reduziu a resultante do transporte longitudinal, ao longo da praia, para uma situação de quase equilíbrio (Muehe \& Corrêa, 1989).

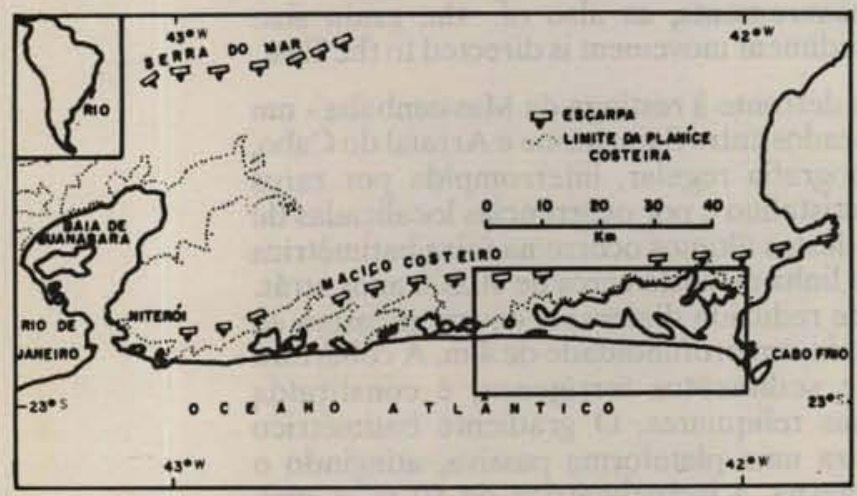

Fig. 1. Localização da área de estudo no litoral sul-oriental do Estado do Rio de Janeiro.

Uma outra característica deste trecho do litoral brasileiro é a ausência de aporte significativo de sedimentos terrígenos devido à barragem das desembocaduras fluviais por cordōes litorâneos. Assim sendo a plataforma continental interna é atapetada por sedimentos reliquiares, principalmente areias, oriundas do retrabalhamento de depósitos aluvionares e da incorporação de sedimentos resultantes da erosão de depósitos do Grupo Barreiras, por ocasião da última transgressão. As fraçōes mais grossas dessas areias permanecem, ainda hoje, na posição de antigas linhas de praia, testemunhando dessa forma a retrogradação da linha de costa (Muehe, 1989).
Os trabalhos, já realizados, sobre aspectos geomorfológicos e sedimentológicos da plataforma continental interna entre a Baía de Guanabara e o Cabo Frio cobrem completamente a área entre Niterói e Ponta Negra (Muehe, op. cit.) e parcialmente entre Ponta Negra e Saquarema (Ponzi, 1978). O objetivo do presente trabalho é o de caracterizar a geomorfologia, a cobertura sedimentar e inferir o transporte de sedimentos de fundo da plataforma continental interna entre a ponta de Saquarema e o Cabo Frio, dando seqüência ao levantamento sistemático da região costeira do Estado do Rio de Janeiro e criando um arcabouço de informaçōes básicas para a elaboração de hipóteses de trabalho cuja verificação demandará a realizaçāo de pesquisas de maior detalhamento.

\section{Metodologia}

Os trabalhos de campo consistiram da amostragem de sedimentos e da realização de perfis batimétricos, sísmicos e de sonar de varredura lateral (Fig. 2). Para este fim foram realizadas três expediçōes com navios oceanográficos, duas campanhas com barco inflável, apoiado em traineira, para a cobertura da faixa entre a zona de arrebentação e a batimétrica de $25 \mathrm{~m}$, e coletas próximo à praia, por meio de mergulho. As duas primeiras expediçōes oceanográficas foram realizadas com o Av. Pesq. Oc. "Suboficial Oliveira" da DHN, em março e abril de 1986, e consistiram na Operação GEOCOSTA RIO II, realizada no âmbito do Programa de Geologia e Geofísica Marinha (PGGM). A terceira foi realizada em janeiro e fevereiro de $1991 \mathrm{com}$ o navio oceanográfico alemão "Victor Hensen", em projeto de cooperação internacional.

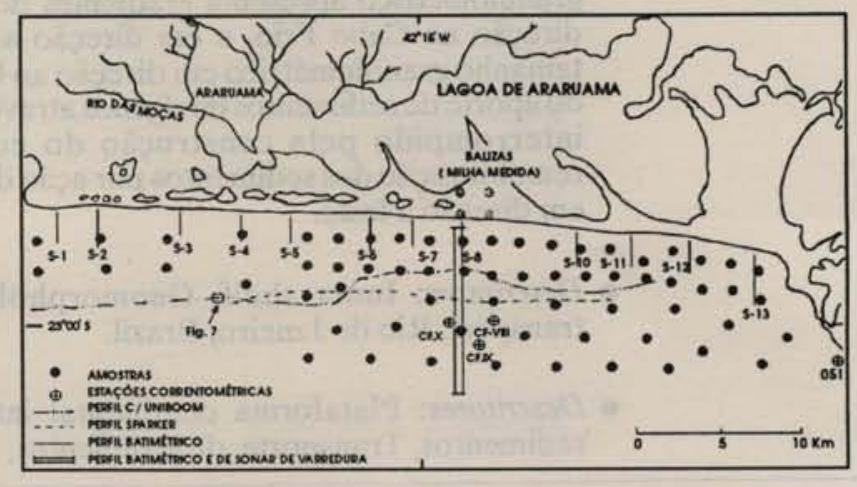

Fig. 2. Localização das estações de amostragem de sedimentos, das estações correntométricas e da localização dos perfis batimétricos, sísmicos e de sonar de varredura lateral. 
Dados sobre medições correntométricas foram obtidos no Banco Nacional de Dados Oceanográficos da Diretoria de Hidrografia e Navegaçāo (BNDO/DHN) referentes às Comissōes Cabo Frio IX e X, e no Instituto de Estudos do Mar Almirante Paulo Moreira (IEAPM) referente às Comissões $051 \mathrm{e}$ Cabo Frio VIII. Dados sobre ondas foram obtidos de Ocean Wave Statistics (Hogben \& Lumb, 1967).

\section{Hidrodinâmica}

As mediçōes correntométricas foram realizadas com o navio oceanográfico "Almirante Saldanha" em locais com profundidades variando entre 50 e $78 \mathrm{~m}$ (Fig. 2). Como o objetivo dessas mediçōes nāo era a determinação de velocidades críticas de transporte de sedimentos, elas foram realizadas a uma distância do fundo entre 9 e $28 \mathrm{~m}$ (Tab. 1), estando, portanto, já fora da camada limite o que torna a estimativa da velocidade de cisalhamento muito imprecisa.

Tabela 1. Características das estações correntométricas

\begin{tabular}{cccc} 
Comissăo & Localização & $\begin{array}{c}\text { Dist. do } \\
\text { Fundo }\end{array}$ & Data \\
\hline 051 & $23^{\circ} 01^{\prime} 2$ S-042 $00^{\circ} 7 \mathrm{~W}$ & $28 \mathrm{~m}$ & $10.09-21.09 / 1972$ \\
Cabo Frio VIII & $23^{\circ} 00^{\prime} 0$ S-042 $12^{\prime} 5 \mathrm{~W}$ & $15 \mathrm{~m}$ & $16.01-23.01 / 1986$ \\
Cabo Frio XX & $23^{\circ} 00^{\prime} 8 \mathrm{~S}-042^{\circ} 13^{\prime} \mathrm{OW}$ & $10 \mathrm{~m}$ & $28.11-08.12 / 1986$ \\
Cabo Frio X & $23^{\circ} 00^{\prime} \mathrm{O}$ S-042 $14^{\circ} \mathrm{O} \mathrm{W}$ & $9 \mathrm{~m}$ & $24.06-27.06 / 1987$ \\
\hline
\end{tabular}

Velocidades críticas de mobilização dos sedimentos, medidas a $100 \mathrm{~cm}$ do fundo, foram estabelecidas experimentalmente por diversos autores (Sundborg, 1956; Sternberg, 1971; Miller et al., 1977), com resultados tendendo a velocidades mais baixas nos trabalhos mais recentes (Fig. 3). A velocidade crítica da corrente, na profundidade em que foi realizada a mediçāo em cada uma das estações correntométricas, foi calculada utilizando a equação de Karman-Prandtl (apud Sundborg, 1956):

$$
\mathrm{U}_{\mathrm{z}}=5,75 \mathrm{U} \cdot \log _{10}\left(\frac{30.2 \cdot \mathrm{Z}}{\alpha \mathrm{K}}\right)
$$

em que

$\mathrm{U}_{\mathrm{z}}=$ velocidade da corrente a uma distância $\mathrm{z}$ do fundo. $U_{\text {. }}=$ velocidade de cisalhamento, segundo Komar (1976), adotando os valores de Gadd et al., (1978) para a velocidade crítica $\left(\mathrm{U}_{100}\right)$.

$$
\mathrm{U}_{\text {. }}=5,47 \times 10^{-2} \mathrm{U}_{100}
$$

$\mathrm{K}=$ altura das irregularidades do fundo. No caso de fundos arenosos lisos corresponde ao $25^{\circ}$ percentil da distribuiçāo granulométrica, de modo que $75 \%$ da distribuição é de material mais fino. Foi adotado o valor de $0,05 \mathrm{~cm}$.

$v=$ viscosidade cinemática. Para temperatura de água de $19^{\circ} \mathrm{C}$, salinidade de 36 e pressão de $50 \mathrm{db}, v=0,011 \mathrm{~g}$ $\mathrm{cm}^{-1} \mathrm{~s}^{-1}$.

$\alpha=$ fator de correção em função de $U_{*}, K_{s}$ e $v . O$ valor encontrado no gráfico da função em Swift $(1976$, p. 96) foi de 0,8 .

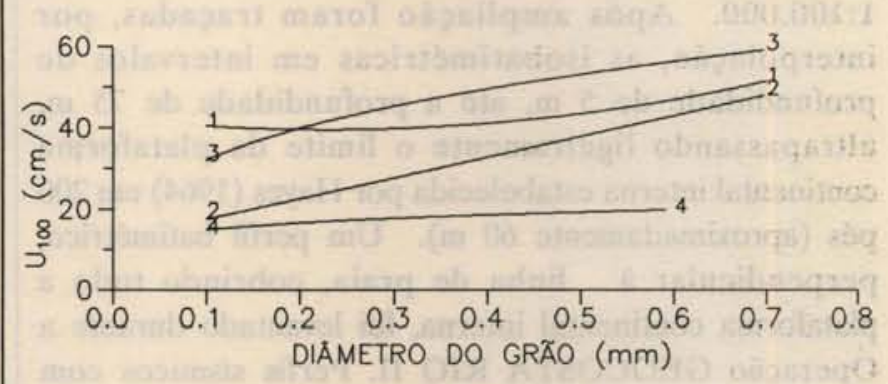

Fig. 3. Velocidades críticas $\left(U_{100}\right)$ de mobilização de sedimentos com densidade de $2,65 \mathrm{~g} \mathrm{~cm}^{-3}$ e diâmetros variados segundo Sundborg, 1956 (1); Sternberg, 1971 (2); Miller et al., 1977; (3) e Gadd et al., 1978 (4).

A capacidade de mobilização dos sedimentos de fundo por ação de ondas foi avaliada através do cálculo da profundidade máxima que uma dada onda, de altura e período conhecido, é capaz de mobilizar um sedimento de determinado tamanho e densidade. Essa profundidade foi calculada utilizando um programa apresentado por Komar \& Miller (1975) e que, para sedimentos de diâmetro inferior a $0,05 \mathrm{~cm}$, emprega a equação:

$$
h=\frac{L_{0}}{2 \pi} \quad \operatorname{arcsenh}\left(\frac{\pi H}{T U_{m}}\right)
$$

onde

$$
\mathrm{L}_{0}=1,56 \cdot \mathrm{T}^{2}
$$




$$
\mathrm{U}_{\mathrm{m}}=\left(0.21\left(\rho_{\mathrm{s}}-\rho\right) \frac{\mathrm{g}}{\rho \pi^{0.5}}\right)^{0.66} \mathrm{D}^{0.33} \mathrm{~T}^{0.33}
$$

sendo que:

$\mathbf{h}=$ profundidade máxima de mobilização dos sedimentos

$L_{o}=$ comprimento da onda não afetada pelo fundo

$\mathrm{H}=$ altura da onda

$T=$ período da onda

$\mathrm{U}_{\mathrm{m}}=$ velocidade orbital crítica

$\mathrm{d}=$ profundidade da água

$\rho=$ densidade da água

$\rho_{\mathrm{S}}=$ peso específico do sedimento

$\mathrm{D}=$ diâmetro dos grãos

$\mathrm{g}=$ aceleração da gravidade

\section{Geomorfologia}

A confecção do mapa batimétrico foi realizada a partir da Folha de Bordo FB - 1500/00179 editada pela Diretoria de Hidrografia e Navegação (DHN) na escala de 1:100.000. Após ampliação foram traçadas, por interpolação, as isobatimétricas em intervalos de profundidade de $5 \mathrm{~m}$, até a profundidade de $75 \mathrm{~m}$, ultrapassando ligeiramente o limite da plataforma continental interna estabelecida por Hayes (1964) em 200 pés (aproximadamente $60 \mathrm{~m}$ ). Um perfil batimétrico, perpendicular à linha de praia, cobrindo toda a plataforma continental interna, foi levantado durante a Operação GEOCOSTA RIO II. Perfis sísmicos com Uniboom e sparker, ao longo da faixa batimétrica de 40-60 m e um perfil de sonar de varredura lateral, perpendicular à costa, foram realizados com o navio "Victor Hensen". Com um barco inflável foram levantados 12 perfis batimétricos, também perpendiculares à costa, cobrindo a faixa entre a arrebentação e a profundidade de $25 \mathrm{~m}$, caracterizando assim a shoreface, zona de transição entre a zona de surfe e a plataforma continental interna propriamente dita (Fig. 2).

\section{Sedimentos de fundo}

As amostras de sedimentos arenosos foram coletadas por draga de arrasto tipo Gibbs. Na faixa batimétrica mais profunda, com predomínio de sedimentos lamosos, foi empregado um busca-fundo do tipo Van Veen. O espaçamento entre as amostras, no sentido perpendicular à costa, foi de 0,5 milhas náuticas entre a zona de arrebentação e a isóbata de $25 \mathrm{~m}$, de 1 milha náutica até a isóbata de $45 \mathrm{~m}$ e de 2 milhas náuticas até a isóbata de 70 m. No sentido transversal o espaçamento foi de 2 milhas náuticas na zona mais rasa e de 1 milha náutica nas profundidades superiores a $25 \mathrm{~m}$.

No laboratório foram efetuadas análises granulométricas, de minerais pesados e de foraminíferos.

As análises granulométricas foram realizadas, por meio de peneiramento a seco da fração areia e pipetagem da fração silte, sendo os resultados expressos através dos parâmetros estatísticos da distribuição granulométrica calculados pelo método de Folk \& Ward (1957). Apesar da, em geral, reduzida presença de fraçōes carbonáticas, estas foram removidas por introduzirem alteraçōes nas curvas de distribuição granulométricas não condizentes com as respostas dos sedimentos terrígenos aos processos hidrodinâmicos atuantes.

As análises de minerais pesados se restringiram à determinação do teor destes minerais na fração entre 0,25 e $0,125 \mathrm{~mm}$ (areia fina), sendo a separação feita por meio de bromoformio. As amostras analisadas se distribuíram ao longa da faixa batimétrica de 40 a $45 \mathrm{~m}$, eliminando assim as variaçôes derivadas de efeitos hidrodinâmicos em diferentes profundidades.

Finalmente a análise dos foraminíferos teve como objetivo verificar a presença, nestes organismos, de carapaças limonitizadas o que seria, segundo Mahiques (1987), um indicador de exposição subárea e de não retrabalhamento subseqüente. As amostras analisadas foram as mesmas das escolhidas para a determinação do teor de minerais pesados.

\section{Resultados}

\section{Geomorfologia}

A disposiçāo, sem grandes inflexōes, das curvas batimétricas mostra uma plataforma continental interna bastante monótona (Fig. 4). A largura desta plataforma, ao contrário do que se poderia esperar, é inversamente proporcional à largura da planície costeira adjacente. Enquanto esta se alarga em direçāo ao Cabo Frio aquela se reduz gradativamente de 5,7 milhas náuticas $(10,5 \mathrm{~km})$, na altura de Saquarema, a oeste, para 2,6 milhas náuticas $(4,8 \mathrm{~km})$ na altura do Cabo Frio. A comparação da curva de distribuição das freqüências de larguras medidas, na área de estudo, com aquelas estabelecidas por Hayes (1964) para plataformas continentais internas (Fig. 5), mostra uma largura atípica para uma plataforma continental do tipo passivo já que a posição da curva obtida se ajusta melhor à curva "A", característica, segundo Hayes, de bordas continentais com relevo montanhoso, jovem e instável, afetadas pela orogênese cenozóica, como as Rochosas e os Andes, do que à curva "B", típica para escudos estáveis, não basculados por movimentos cenozóicos, como, por exemplo, a África oriental. 


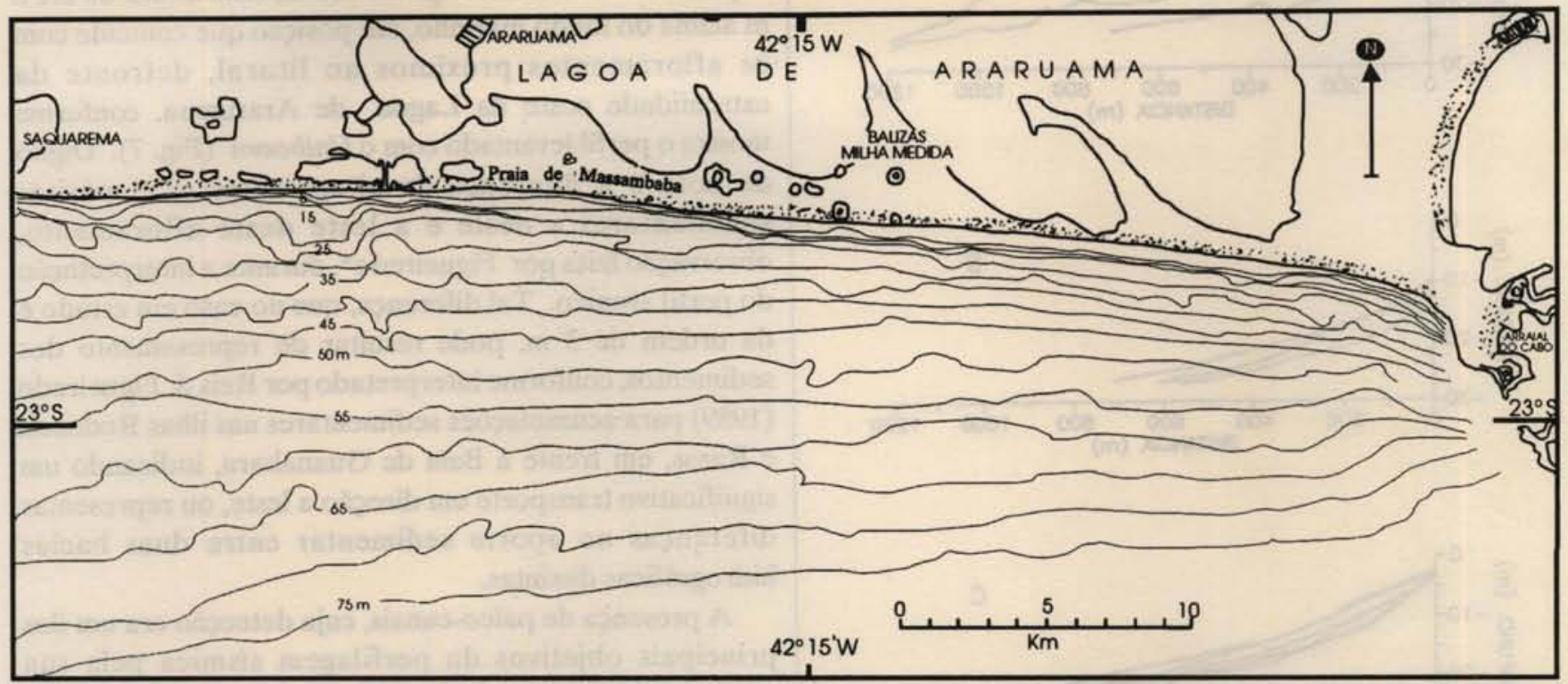

Fig. 4. Disposição das curvas batimétricas na plataforma continental interna entre Saquarema e Arraial do Cabo.

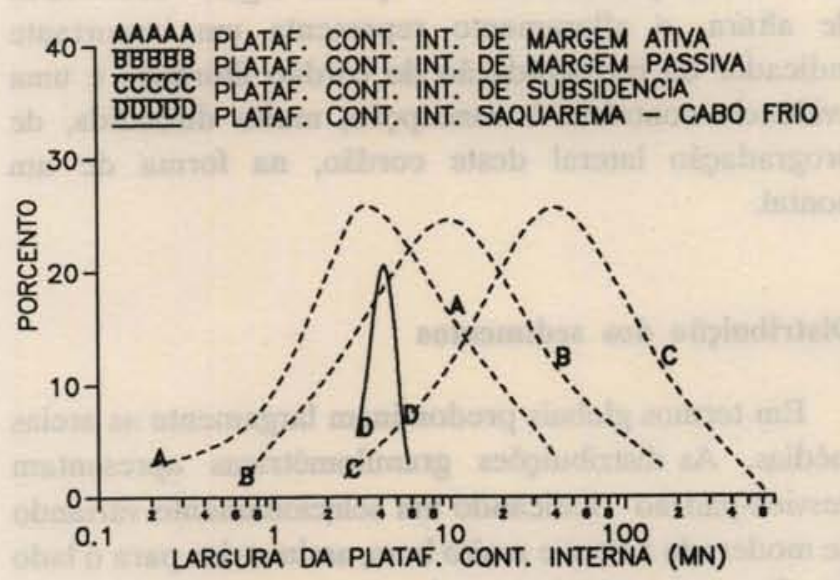

Fig. 5. Comparação entre a largura da plataforma continental interna da área de estudo com distribuições típicas de plataformas do tipo passivo, ativo e de subsidência (segundo Hayes, 1964).

Nas proximidades do litoral, a regularidade topográfica é interrompida, na extremidade oeste da área de estudo, no trecho entre Saquarema e o início da Lagoa de Araruama, onde elevaçōes topográficas do embasamento cristalino afloram no fundo marinho como testemunhos da retrogradação da linha de costa (Fig. 6-A perfis S-1, S-2 e S-3). Estes afloramentos, favoráveis à pesca de fundo, afetam o gradiente batimétrico da shoreface, que se apresenta irregular e menos íngreme que mais a leste. Segue-se uma zona de transição, representada pelos perfis $S-4, S-5$ e $S-6$, já sem afloramentos porém com gradientes batimétricos um pouco maiores que no restante da área (Fig. 6-B), e finalmente o trecho mais a leste, (perfis S-7 a S-13), caracterizado por um gradiente batimétrico suave (Fig. 6-C) antecedendo o trecho de praia do tipo dissipativo. O limite da shoreface, nem sempre muito nítido, se estabelece em torno de 16 a $20 \mathrm{~m}$ de profundidade.

Afloramentos rochosos, sem grande expressāo vertical, mas responsáveis pela virgação da curva batimétrica de $50 \mathrm{~m}$, ocorrem no limite externo da faixa central da plataforma continental interna, praticamente no alinhamento oeste das balizas da "milha medida" (Fig. 4). O perfil batimétrico da Figura 6-D mostra a alteração da declividade do fundo marinho pelo citado afloramento, a uma distância de 4,8 a $7 \mathrm{~km}$ da costa e profundidades entre $48 \mathrm{a} 60 \mathrm{~m}$, cuja presença se caracterizou pelo aparecimento de amostras de fauna típica de substrato duro. O perfil sísmico, levantado com o sparker, comprovou que no local destes afloramentos o embasamento cristalino se mantém em profundidades entre 30 e $40 \mathrm{~m}$ da superfície do fundo, não podendo assim se tratar de afloramento de rochas do cristalino. Com isto é reforçada a interpretação do perfil de sonar de varredura lateral que indica ser o afloramento 

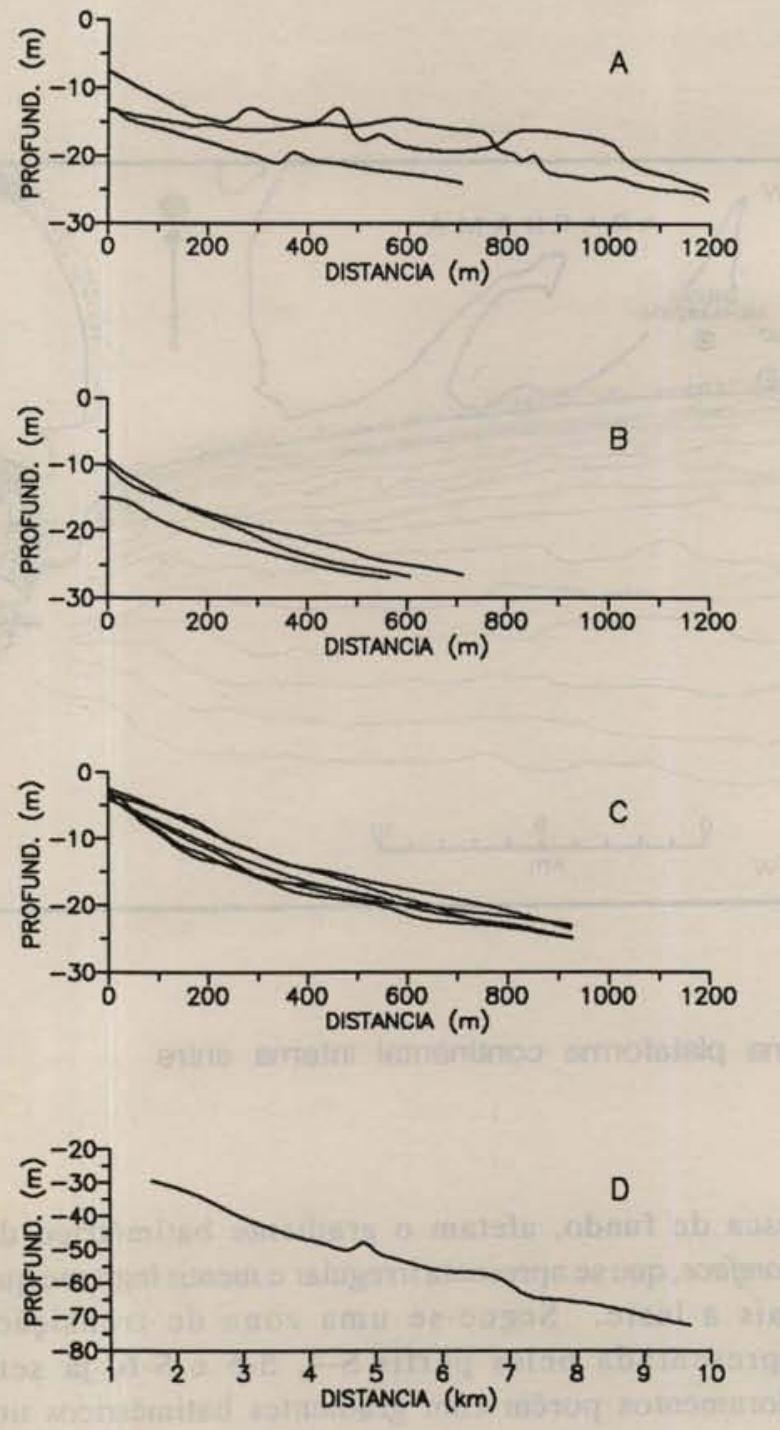

Fig. 6. De A a C perfis batimétricos da shoreface entre Saquarema e Arraial do Cabo. O início de cada perfil se localiza nas proximidades da linha de arrebentação. Em D um perfil batimétrico transversal à plataforma continental interna mostrando a alteração do gradiente topográfico pela presença de afloramentos de arenitos de praia.

composto por arenitos de praia (beach rocks), atestando desta forma a posição de uma antiga linha de costa, possivelmente correspondente a uma posição intermediária entre as estabilizaçōes do nível do mar, há cerca de 11000 e 9000 anos, inferidas, por Kowsmann \& Costa (1979), para outras áreas da plataforma continental brasileira, correspondente a níveis batimétricos de, respectivamente, 60 e $40 \mathrm{~m}$. Na área de estudo a ausência de uma nítida ruptura do gradiente batimétrico não permitiu a deteç̧ão destes níveis de estabilização através de mapeamento batimétrico de detalhe, conforme ressaltado por Costa et al. (1988). Cerca de $15 \mathrm{~km}$ mais para oeste, ainda ao longo da batimétrica de $50 \mathrm{~m}$, o embasamento cristalino começa a se aproximar da superfície e aflora ao longo de $800 \mathrm{~m}$, com altura de até 6 $\mathrm{m}$ acima do fundo marinho, em posição que coincide com os afloramentos próximos ao litoral, defronte da extremidade oeste da Lagoa de Araruama, conforme mostra o perfil levantado com o Uniboom (Fig. 7). Digno de nota é a diferença de altura entre os depósitos sedimentares a oeste e a leste deste afloramento, observação feita por Figueiredo*, durante a interpretação do perfil sísmico. Tal diferença, que no caso em estudo é da ordem de $3 \mathrm{~m}$, pode resultar de represamento dos sedimentos, conforme interpretado por Reis \& Figueiredo (1989) para acumulaçōes sedimentares nas ilhas Redonda e Rasas, em frente à Baía de Guanabara, indicando um significativo transporte em direção a leste, ou representar diferenças no aporte sedimentar entre duas bacias hidrográficas distintas.

A presença de paleo-canais, cuja detecção era um dos principais objetivos da perfilagem sísmica pela sua comprovação como fornecedores de sedimentos, não pôde, pelo menos numa primeira análise, ser inferida devido á baixa resolução obtida.

Junto à costa, cerca de $50 \mathrm{~m}$ da linha de praia e próximo à posiçāo do perfil S-4, foi localizado outro afloramento de arenitos de praia. Com otopo a cerca de $4 \mathrm{~m}$ de profundidade e apenas alguns decímetros de altura, o afloramento representa um importante indicador da retrogradaçāo do cordāo litorâneo e uma evidência contrária à concepção, muito difundida, de progradação lateral deste cordāo, na forma de um pontal.

\section{Distribuição dos sedimentos}

Em termos globais predominam largamente as areias médias. As distribuiçōes granulométricas apresentam desvios-padrão indicando um selecionamento variando de moderado a bom e muito bom, assimetrias para o lado dos finos em mais da metade das amostras e a curtose variando amplamente entre leptocúrtica, platicúrtica e mesocúrtica (Fig. 8).

Em termos espaciais a distribuição dos parâmetros granulométricos apresenta o seguinte padrão:

i. o diâmetro médio granulométrico se caracteriza por um predomínio da areia média entre a praia e a batimétrica de $45 \mathrm{~m}$, com exceçâo da extremidade leste da área de estudo, nas proximidades de Arraial do Cabo, onde passa a predominar a areia fina (Fig. 9). Em profundidades superiores a $50 \mathrm{~m}$ predomina a areia muito fina. Areia grossa ocorre no extremo oeste

(*) Figueiredo Jr, A. G. de (1991) Instituto de Geociências UFF, Niterói. 


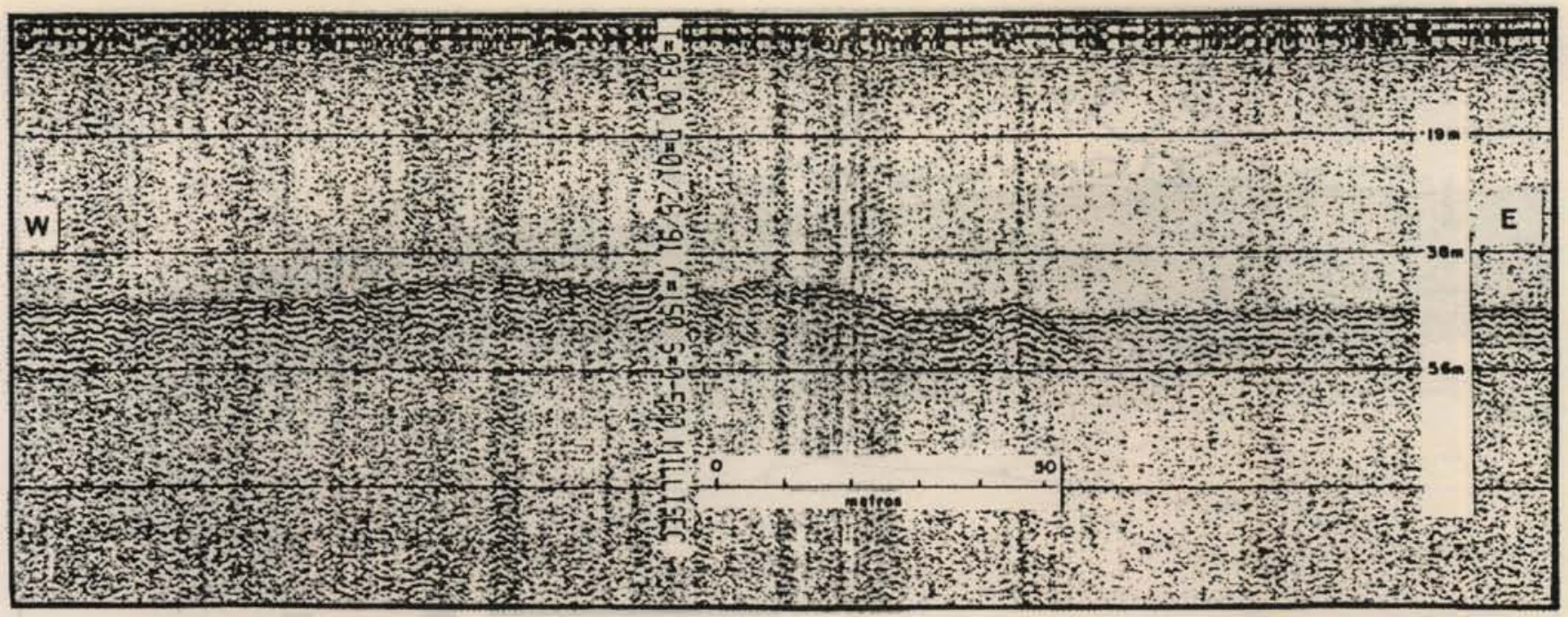

Fig. 7. Afloramento do embasamento cristalino indicando compartimentação topográfica da plataforma continental interna idêntica à da planície costeira. A maior acumulação de sedimentos no flanco oeste do afloramento pode ser indicador de transporte sedimentar em direção ao Cabo Frio ou de taxas diferenciadas de aporte de sedimentos continentais.

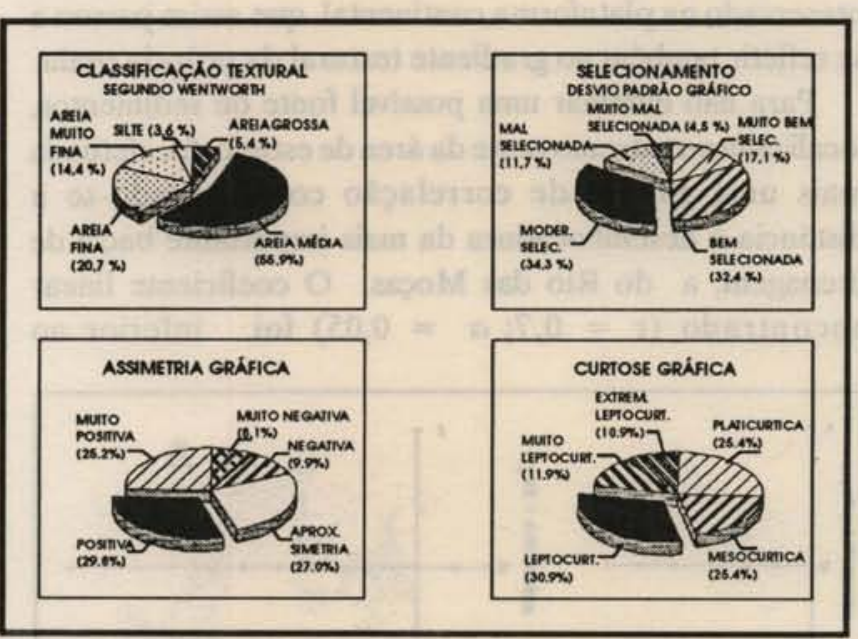

Fig. 8. Caracterização dos sedimentos de acordo com os parâmetros granulométricos.

da área e em pontos isolados na porção mais central, possivelmente em função da proximidade das elevaçōes rochosas observadas, podendo assim representar restos de depósitos coluvionais retrabalhados, ou, então, proximidades de depósitos associados a paleo-canais. Sedimentos silticos ocorrem no extremo sudeste e em uma amostra na porção central da área de estudo, sempre em profundidades superiores a $65 \mathrm{~m}$, portanto, a rigor, já fora da plataforma continental interna.
A diminuiçāo do tamanho granulométrico, de oeste para leste, se dá, com algumas oscilações em torno de uma tendência geral de decréscimo gradativo conforme mostra a Figura 10. Nesta é representado o comportamento do $1^{\circ}$, do $50^{\circ}$ e do $99^{\circ}$ percentil das distribuiçōes granulométricas de amostras localizadas na faixa batimétrica entre 40 e $45 \mathrm{~m}$.

ii. o desvio padrão, seguindo o gradiente de decréscimo granulométrico, se apresenta moderadamente selecionado na metade oeste da área de estudo, passando para bem e muito bem selecionado, na metade leste. Em profundidades superiores a $50 \mathrm{~m}$, com o aparecimento de fraçōes granulométricas finas, os sedimentos se apresentam mal a muito mal selecionados.

iii. a distribuição do valor da assimetria não mostrou tendência definida em termos espaciais. Quando correlacionada graficamente com o diâmetro médio granulométrico (Fig. 11-A) apresentou a mesma amplitude de variaçāo entre 2 e $3 \Phi$ e o início de uma senóide entre 3 e $4 \Phi$ (Fig. 11-B), como encontrados por Ponçano (1986).

\section{Área fonte e transporte de sedimentos}

O gradativo afinamento dos sedimentos em direção a leste sugere de imediato uma acentuada tendência de transporte residual em direção ao Cabo Frio. Se, entretanto, correlacionarmos o tamanho granulométrico 


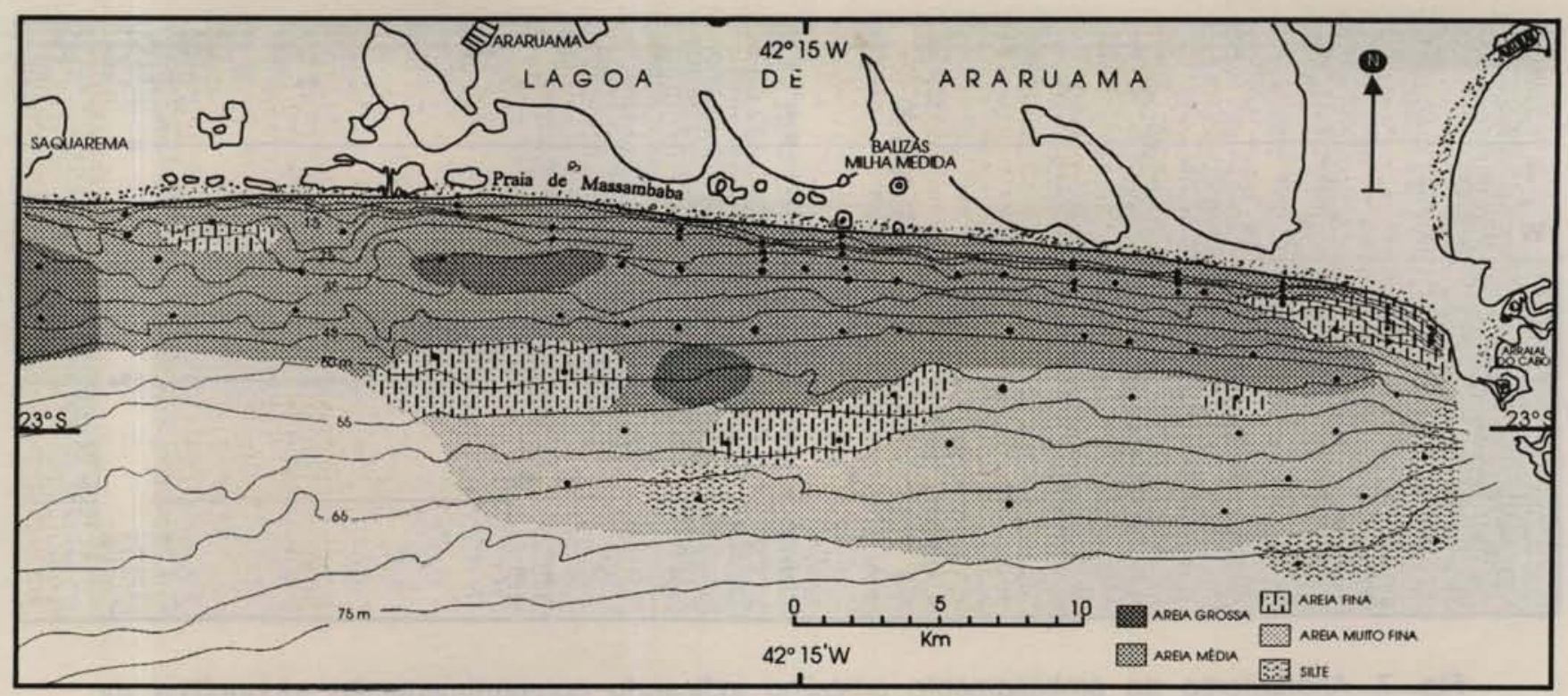

Fig. 9. Distribuição espacial dos sedimentos de acordo com a classificação textural de Wentworth (1922).

médio dos sedimentos, expresso em $\Phi$, coletados ao longo da faixa batimétrica de $40 \mathrm{a} 45 \mathrm{~m}$, com a distância à linha de costa existente antes da construçāo da restinga, no caso a borda frontal do maciço costeiro, obtem-se um significativo coeficiente linear positivo $(r=0,8 ; \alpha=0,01$; coeficiente angular $=0,433$ ). Isto mostra que o afinamento pode, em grande parte, ser explicado pelo aumento da distância à área fonte, considerando como tal o maciço costeiro no litoral norte da Lagoa de Araruama. Se, por outro lado, a correlação entre tamanho médio granulométrico e distância à linha de costa for realizado para a atual linha de praia, isto é, a Praia da Massambaba, obtêm-se uma correlação linear inversa $(r=0,7 ; \alpha=0,03$; coeficiente angular $=0,203$ ). Esta mesma relaçāo, também é encontrada para os sedimentos da shoreface, podendo ser interpretrada, como indicação de que o cordâo litorâneo, que constitui a Praia da Massambaba,

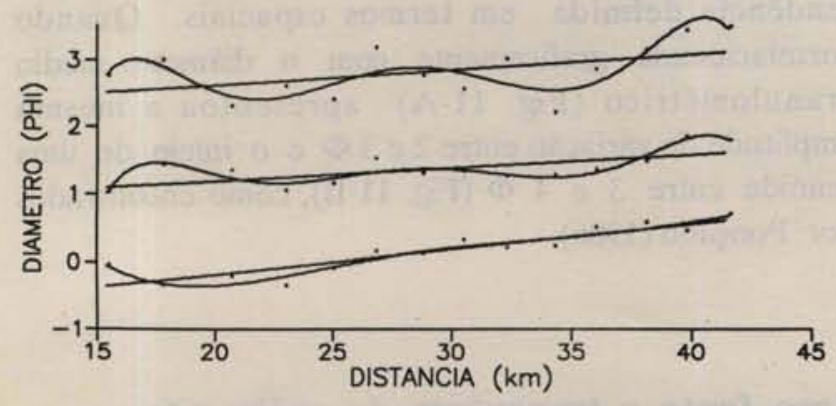

Fig. 10. Ajuste polinomial de grau 1 e 6 do gradiente de decréscimo granulométrico do $1^{\circ}, 50^{\circ}$ e $99^{\circ}$ percentil, em direção ao Cabo Frio, ao longo da faixa batimétrica de $40 \mathrm{e}$ $45 \mathrm{~m}$. teve sua origem numa posição de nível de mar mais baixo, interceptando o padrão granulométrico reliquiar preservado na plataforma continental que assim passou a se refletir também no gradiente textural da própria praia.

Para não eliminar uma possível fonte de sedimentos, localizada no extremo oeste da área de estudo, foi efetuada mais uma análise de correlação considerando-se a distância à desembocadura da mais importante bacia de drenagem, a do Rio das Moças. O coeficiente linear encontrado $(r=0,7 ; \alpha=0,05)$ foi inferior ao

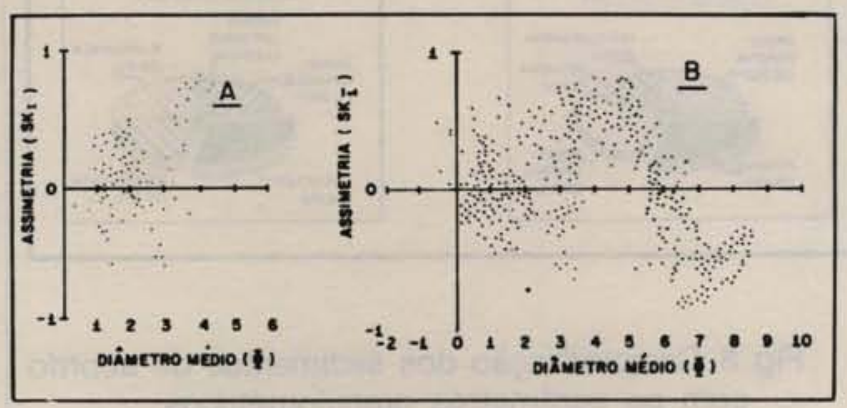

Fig. 11. Correlação gráfica entre o diâmetro médio granulométrico e a assimetria de amostras da plataforma continental interna da área de estudo (A) e de amostras de sedimentos quaternários da costa brasileira (B) apresentada por Ponçano (1986). A semelhança de distribuição, para os mesmos intervalos granulométricos, confirma a relação entre assimetria e tamanho médio granulométrico e comprova a inadequação do valor da assimetria, como indicador de transporte, quando analisado isoladamente. 
determinado para a borda oceânica do maciço costeiro como um todo, além de apresentar um baixíssimo coeficiente angular, correspondente a uma inclinação da reta de regressão de pouco menos de $2^{\circ}$. Isto sugere a existência de aporte sedimentar à antiga planície, atual plataforma continental, através de vários canais de escoamento dispostos ao longo da linha de costa, e não através de apenas uma única fonte.

Uma questão que se impōe, a partir das interpretaçōes acima, é se a origem do gradiente de afinamento granulométrico de fato se resume a apenas um presumível padrão herdado. $\mathrm{O}$ aspecto trabalhado dos grãos de quartzo e a ausência de limonitização de carapaças de foraminíferos indicam condiçōes hidrodinâmicas favoráveis à mobilização dos sedimentos. A presumível existência de numerosos paleo-canais não pôde, até o momento, ser comprovada pelos perfis sísmicos. Resta então verificar se o padrão granulométricoé de fato apenas resultado da distância à retroterra ou se mecanismos de mobilização dos sedimentos atuam no sentido de imprimir uma resultante de transporte responsável pela consolidação do padrão textural supostamente herdado. Esta verificação será realizada através de uma reavaliação na interpretação do padrão de distribuição dos parâmetros granulométricos e na análise de dados correntométricos e de ondas.

Reinterpretação dos parâmetros granulométricos como indicador de transporte: aplicação da teoria de McLaren

McLaren (1981) apresentou um modelo de interpretação dos parâmetros granulométricos baseado nas modificaçōes relativas destes parâmetros em função de uma presumida área fonte. Assim, a assimetria, por exemplo, não seria diagnosticamente importante em seus valores absolutos mas sim por sua tendência de mudança relativa à fonte ao longo da trajetória de transporte, o mesmo ocorrendo com a média e o desvio padrão. $\mathrm{Na}$ Figura 12 é apresentado um esquema demonstrativo de interpretação dos parâmetros estatísticos no sentido de identificaçāo de áreas fonte segundo McLaren (op. cit.).

Os resultados obtidos sugerem, para os perfis perpendiculares ao litoral, um predomínio de transporte em direção à costa, sendo que $51 \%$ das amostras indicaram uma relaçâo fonte-depósito do oceano para a costa, 33\% da costa para o oceano e $16 \%$ foram excluídas por apresentarem características incoerentes com o hidrodinamismo do local de amostragem. Observa-se ainda que, enquanto o transporte parece ser nitidamente direcionado para a costa na metade oeste da área de estudo, a metade leste apresenta, em geral, um equilibrio entre as duas direçōes de transporte com exclusão da extremidade leste, caracterizada pela presença de areias muito finas, onde a comparação entre os parâmetros granulométricos sugere transporte em direção ao oceano aberto em todas as amostras analisadas.

Para os perfis paralelos ao litoral, $51 \%$ das amostras indicaram transporte para leste, $18 \%$ transporte para oeste e $31 \%$ das amostras foram desconsideradas. As amostras analisadas se situaram nas faixas batimétricas de 15, 20,30, 40, 50 e $60 \mathrm{~m}$. Destas apenas as situadas na batimétrica de $50 \mathrm{~m}$ apresentaram uma resultante de transporte para oeste.

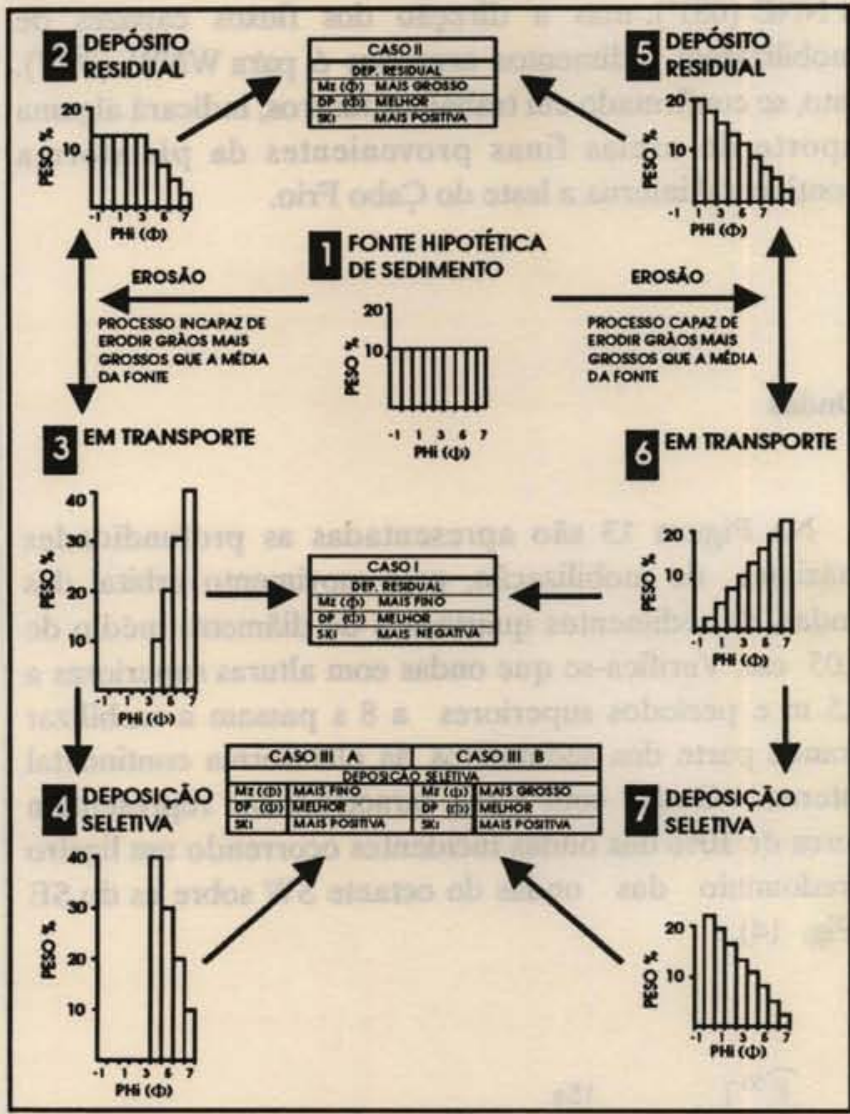

Fig. 12. Esquema representativo das modificações dos parâmetros granulométricos em função de erosão, transporte e deposição, segundo McLaren (1981).

\section{Correntometria}

As estaçōes das Comissōes Cabo Frio se localizam todas no prolongamento das balizas da "milha medida", em profundidades da ordem de $60 \mathrm{~m}$, ao passo que a estação da Comissão 051 se localiza bem defronte da extremidade sul da Ilha de Cabo Frio, em águas com $78 \mathrm{~m}$ de profundidade (Fig. 2).

A tendência geral, das medições realizadas nas estaçōes das Comissōes Cabo Frio, é o de apresentar resultantes dos fluxos, tanto críticos quanto subcríticos, 
direcionados para o quadrante SE, reforçando a hipótese de um transporte em direção a leste. Exceção constitui a estação da Comissão IX, realizada no final da primavera, que apresenta resultante direcionada para NNW sem, no entanto, atingir a velocidade crítica de mobilização dos sedimentos.

A estação da Comissão 051 apresenta flutuaçōes de velocidade da corrente que atingem valores de até 120 $\mathrm{cm} \cdot \mathrm{s}^{-1}$, que é superior à velocidade encontrada no núcleo da Corrente do Brasil. Trata-se provavelmente de erro instrumental. A resultante geral dos fluxos é em direção a NNE $\left(031^{\circ}\right)$, mas a direção dos fluxos capazes de mobilizarem sedimentos arenosos é para WNW $\left(392^{\circ}\right)$. Isto, se confirmado em trabalhos futuros, indicará alguma aporte de areias finas provenientes da plataforma continental interna a leste do Cabo Frio.

\section{Ondas}

Na Figura 13 são apresentadas as profundidades máximas de mobilização, pelo movimento orbital das ondas, de sedimentos quartzosos de diâmetro médio de $0,05 \mathrm{~cm}$. Verifica-se que ondas com alturas superiores a $2,5 \mathrm{~m}$ e períodos superiores a $8 \mathrm{~s}$ passam a mobilizar grande parte dos sedimentos da plataforma continental interna. Ondas com estas características representam cerca de $10 \%$ das ondas incidentes ocorrendo um ligeiro predomínio das ondas do octante SW sobre as do SE (Fig. 14).

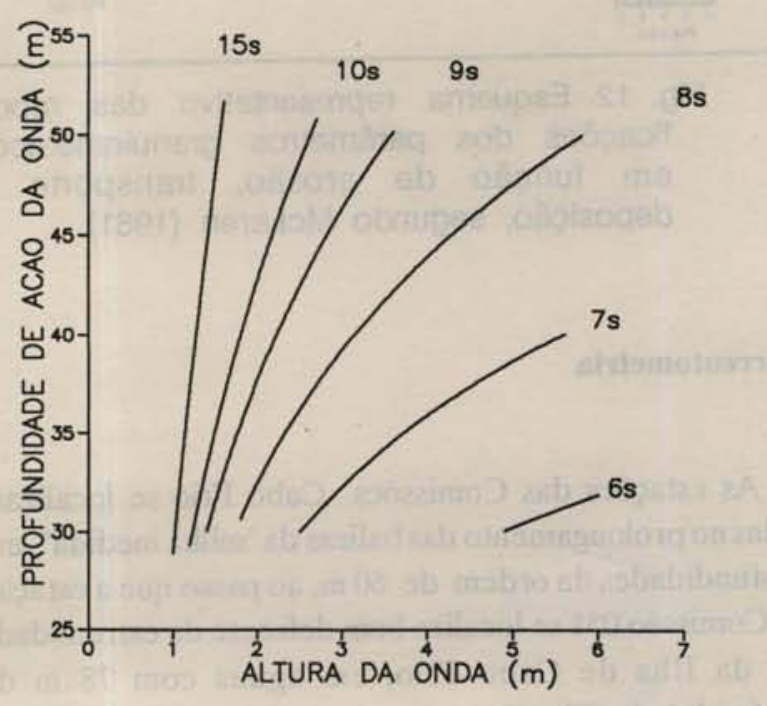

Fig. 13. Profundidades máximas de mobilização, por ação das ondas, de sedimentos de 0,05 $\mathrm{cm}$ de diâmetro e densidade de $2,65 \mathrm{~g}^{\mathrm{cm}} \mathrm{cm}^{-3}$.

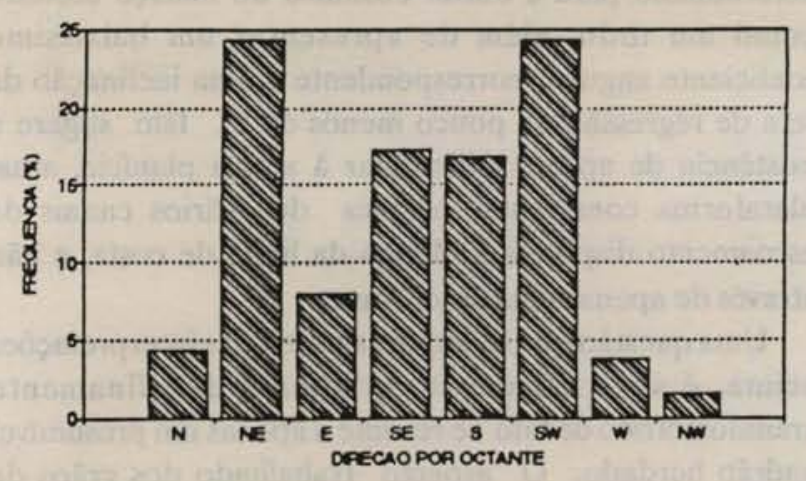

Fig. 14. Freqüência de incidência, por direção de ondas com altura superior a $2,5 \mathrm{~m}$ e período superior a $8 \mathrm{~s}$.

Mais importante que um ligeiro deslocamento dos sedimentos na direção de propagaçāo das ondas é o efeito de mobilização dos mesmos, fazendo com que uma corrente unidirecional, mesmo com velocidade subcrítica, possa provocar transporte. Neste sentido, a combinação entre açāo das ondas e fluxo unidirecional de correntes de fundo reforça, para a área em estudo, a hipótese de predomínio de transporte em direção a leste.

Um mecanismo, cuja influência ainda não foi determinada, é o da ação de ondas de grande período, como as "edge waves" (Munk et al., 1964). Tais ondas poderiam provocar substancial transporte de sedimentos.

\section{Conclusão}

Ponto de brusca inflexão das linhas batimétricas, com conseqüente instabilização da Corrente do Brasil, o Cabo Frio representa também um limite oceanográfico entre características tropicais e subtropicais. A orientação das isobatimétricas, a oeste do referido cabo, aproximadamente normal à direção das ondas de tempestades, imprimiu idêntica direção aos cordōes litorâneos e faz com que o balanço do transporte longitudinal de sedimentos, ao longo da linha de praia, seja praticamente nulo (Muehe \& Corrêa, 1989). A discrepância entre a direção, ENE-WSW, da linha de costa antes da construçāo dos cordōes litorâneos, e a direçāo E-W deste últimos, levou a um alargamento da planície costeira em direçāo ao Cabo Frio, em grande parte ocupada pela Laguna de Araruama, estabelecendo-se, como conseqüência, uma relação inversa entre a largura da planície costeira e a largura da plataforma continental interna. Esta última, quando comparada com a largura de outras plataformas continentais internas, se aproxima mais da largura modal de plataformas internas típicas de 
margem continental ativa do que de margem passiva, sugerindo a ocorrência de eventos tectônicos mais recentes que os da fase rift.

Geomorfologicamente a plataforma interna se caracteriza por uma relativa homogeneidade topográfica. Afloramentos do embasamento cristalino são raros e, quando existentes, coincidem com a posição de interfluvios responsáveis pela compartimentaçāo das planícies costeiras. Arenitos de praia ocorrem em pontos isolados, se apresentando de forma pronunciada nas proximidades da batimétrica de $50 \mathrm{~m}$, caracterizando uma antiga posiçāo do nível do mar, e em pequena extensāo a oeste, a pouca distância da arrebentação, atestando a retrogradaçāo do cordão litorâneo frontal.

A ausência de aporte de sedimentos continentais devido ao bloqueio dos cordōes litorâneos, caracteriza a cobertura sedimentar, essencialmente composta por areias quartzosas, como sendo reliquiar. Apresentando um gradiente de decréscimo do tamanho granulométrico em direçāo a leste, os sedimentos da plataforma interna apresentam uma significativa correlação inversa entre o tamanho médio granulométrico e a distância à borda do maciço costeiro, sugerindo ter sido a retroterra mais próxima a principal fonte dos sedimentos. Assim sendo, o afinamento do tamanho granulométrico em direção a leste resulta, primariamente, da distância à área fonte no continente e apenas secundariamente da mobilização seletiva, pós-deposicional. Esta mobilizaçāo, com direçāo resultante para leste, inferida pela análise de dados correntométricos, de ondas e pelos parâmetros granulométricos, constitui-se no mecanismo responsável pela acentuação do padrão de distribuição granulométrico herdado do Pleistoceno superior, a partir do bloqueio, pelos cordôes litorâneos, de uma suposta drenagem voltada para o sul.

\section{Agradecimentos}

O presente trabalho faz parte de um projeto de levantamento geomorfológico da região costeira e plataforma continental interna do Estado do Rio de Janeiro, realizado no âmbito do Programa de Geologia e Geofísica Marina (PGGM). Os recursos financeiros, incluindo Bolsas de Mestrado, Pesquisa e Dedicaçāo Acadêmica, foram concedidos pela Secretaria da Comissão Interministerial para os Recursos do Mar (SeCIRM, Subprojeto 9262), pelo Conselho Nacional de Desenvolvimento Científico e Tecnológico (CNPq, Proc. 300156-78 e 501088/91- (NV)), pela Universidade Federal do Rio de Janeiro (UFRJ, Projeto SAG 310506 P0016), pela Coordenaçāo de Aperfeiçoamento de Pessoal de Nível Superior (CAPES) e pela Fundação de
Amparo à Pesquisa do Estado do Rio de Janeiro (FAPERJ). Pelas facilidades oferecidas na utilização das instalaçōes do Instituto de Pesquisas do Mar Almirante Paulo Moreira (IEAPM) e do Av. Pesq. Oc. "S. O. Oliveira", os autores expressam seus agradecimentos ao Diretor do Instituto, Capitão-de-Mar-e-Guerra Emmanuel Gama de Almeida, ao pesquisador do Instituto, Audálio Rebelo Torres Jr e à tripulaçāo do "S. O. Oliveira", pela ajuda na obtenção dos dados. Ao Dr Alberto Figueiredo, do Departamento de Geologia e Laboratório de Geologia Marinha da Universidade Federal Fluminense os autores expressam seus agradecimentos pela oportunidade de realização de perfis sísmicos e de sonar de varredura lateral em projeto de cooperação Brasil-Alemanha (Projeto JOPS'90/91 - MAR 3.2). Os equipamentos geofísicos utilizados pertencem ao Banco Nacional de Equipamentos Geofísicos (PGGM/LAGEMAR).

\section{Referências bibliográficas}

ASMUS, H. E. \& FERRARI, A. L. 1978. Hipótese sobre as causas do tectonismo Cenozóico na região sudeste do Brasil. In: PETROBRÁs. Aspectos estruturais da margem continental leste e sudeste do Brasil. Rio de Janeiro, CENPES. p. 78-88. (Série Projeto REMAC 4).

COSTA, M. P. de A.; ALVES, E. da C.; PACHECO, P. G. \& MAIA, A. S. 1988. Prováveis estabilizaçōes do nível do mar holocênico em trechos da plataforma continental entre o norte de São Paulo e o sul do Rio de Janeiro, constatadas através de morfologia de detalhe. In: CONGRESSO BRASILEIRO DE GEOLOGLA, 35., Belém, 1988. Anais. Belém, Sociedade Brasileira de Geologia. v.2, p. 436-442.

FOLK, R. L. \& WARD, W. C. 1957. Brazos river bar: a study in the significance of grain size parameters. J. sedim. Petrology, 27(1):3-27.

GADD, P. E.; LAVELLE, J. W. \& SWIFT, D. J. P. 1978. Estimates of sand transport on the New York shelf using near-bottom current meter observations. J. sedim. Petrology, 48(1):239-252.

HAYES, M. O. 1964. Lognormal distribution of inner continental shelf widths and slopes. Deep-Sea Res., 11(1):53-78.

HOGBEN, N. \& LUMB, F. E. 1967. Ocean wave statistics. London, National Physical Laboratory, Ministry of Technology. 
KOMAR, P. D. 1976. The transport of cohesionless sediments on continental shelves. In: Stanley, D. J. \& Swift, D.J.P., eds Marine sediment transport and environmental management. New York, John Wiley. p. 107-125.

\& MILLER, M. C. 1975. On the comparison between the threshold of sediment motion under waves and unidirectional currents with a discussion of the practical evaluation of the threshold. J. sedim. Petrology, 45(1):362-367.

KOWSMANN, R. O. \& COSTA, M. P. A. 1979. Evidence of later quaternary sea level stillstands on the upper Brazilian continental margin: a synthesis. In: INTERNATIONAL SYMPOSIUM ON COASTAL EVOLUTION IN THE QUATERNARY, São Paulo, 1978. Proceedings. São Paulo, Instituto Astronômico e Geofísico. p. 170-192.

MAHIQUES, M. M. de 1987. Consideraçōes sobre os sedimentos de superfície de fundo da Baía da Ilha Grande, Estado do Rio de Janeiro. Dissertaçāo de mestrado. Universidade de São Paulo, Instituto Oceanográfico. 2v. Inédito.

McLAREN, P. 1981. An interpretation of trends in grain size measures. J. sedim. Petrology, $51:(2): 611-624$.

MESQUITA, A. R. de; LEITE, J. B. de A. \& RIZZO, R. 1979. Contribuição ao estudo das correntes marinhas na plataforma entre Cabo Frio e Cananéia. Bolm Inst. oceanogr., S Paulo, 28(2):95-100.

MILLER, M. C.; MCCAVE,I.N. \& KOMAR, P. D. 1977. Threshold of sediment motion under unidirectional currents. Sedimentology, 24:507-527.

MUEHE, D. 1983. Conseqüências higroclimáticas das glaciaçōes quaternárias no relêvo costeiro a leste da Baía de Guanabara. Revta brasil. Geoc., 13(4):245-252.

1989. Distribuição e caracterização dos sedimentos arenosos da plataforma continental interna entre Niterói e Ponta Negra, RJ. Revta brasil. Geoc., 19(1):25-36.

\& CORRÊA, C. H. T. 1989. Dinâmica de praia e transporte de sedimentos na restinga da Maçambaba, RJ. Revta brasil. Geoc., 19(3):387-392.

MUNK, W.; SNODGRASS, S. \& GILBERT, S. 1964. Long waves on the continental shelf: an experiment to separate trapped and leaky modes. J. Fluid Mech., 20(40):529-554.
PONÇANO, W. L. 1986. Sobre a interpretação ambiental de parâmetros estatísticos granulométricos: exemplos de sedimentos quaternários da costa brasileira. Revta brasil. Geoc., 16(2):157-170.

PONZI, V. R. A. 1978. Aspectos sedimentares da plataforma continental interna do Rio de Janeiro entre Saquarema e Ponta Negra. Dissertação de mestrado. Universidade Federal do Rio Grande do Sul, Pós-Graduação em Geociências. 89 p.

REIS, M. C. B. \& FIGUEIREDO JR, A. G. 1989. Interpretaçāo da morfologia de fundo da plataforma continental entre a baía de Guanabara e baía de Sepetiba. In: SIMPÓSIO DE GEOLOGIA DO SUDESTE. Resumos. Rio de Janeiro, Sociedade Brasileira de Geologia. p. 53.

STERNBERG, R. W. 1971. Measurement of incipient motion of sediment particles in the marine environment. Mar. Geol., 10(2):113-119.

SUNDBORG, A. 1956. The river Klarälven, a study of fluvial processes. Geogr. Annlr 38(2):127-316.

SWIFT, D. J. P. 1976. Coastal sedimentation. In: Staley, D. J. \& Swift, D. J. P., eds New York, John Wiley. p.255-310. Marine sediment transport and environmental management.

VANNEY, J. R. 1977. Géomorphologie des plateformes continentales. Paris, Doin Edit. 300p.

WENTWORTH, C. 1922. A scale of grade and class terms for clastic sediments. J. Geol., 30:377-392.

WEISSEL, J. K. 1990. Long term erosional development of rifted continental margins: toward a quantitative understanding. Pacific RIM 90 Congress. The Australian Institute of Mining and Metallurgy. p. 63-70.

(Manuscrito recebido 24 março 1992; revisto 16 março 1993; aceito 7 junho 1993) 